\title{
CONSERVAÇÃO PREVENTIVA, INTERVENÇÃO E RESTAURO EM ACERVO ETNOLÓGICO: SUGESTÕES METODOLÓGICAS
}

\author{
Aivone Carvalho* \\ Dulcília Lúcia de Oliveira Silva*
}

\begin{abstract}
CARVALHO, A.; OLIVEIRA SILVA, D.L. Conservação preventiva, intervenção e restauro em acervo etnológico: sugestões metodológicas. Rev. do Museu de Arqueologia e Etnologia, São Paulo, 15-16: 347-355, 2005-2006.
\end{abstract}

RESUMO: Este artigo teve como fundamento trabalhos e pesquisas realizados no setor de Etnologia do Museu Dom Bosco de Campo Grande, durante o projeto de transferência do acervo para um novo espaço museal, obedecendo a normas e técnicas desenvolvidas a partir de consultorias com especialistas nacionais e internacionais, dos quais citamos: Gedley Braga, Museu de Arqueologia e Etnologia da Universidade de São Paulo, Agostinho Eibajwu e Ayrton Meri Ekureu, Centro de Cultura Bororo da Aldeia de Meruri- Mato Grosso; Dra. Claudia Kusch, restauradora em diversos museus da Itália, principalmente do Museu do Vaticano, e professora do Instituto Central de Restauração de Roma; Axel Nielsen, arqueólogo, professor e restaurador radicado em Roma; Ester Console, curadora do departamento de Etnologia do Museo Missionario Etnologico Vaticano, na Itália.

UNITERMOS: Etnologia brasileira - Conservação e restauração de material etnográfico - Sugestões metodológicas.

Considerando que os museus brasileiros, de um modo geral, lutam contra inúmeros obstáculos para manter a cultura material sob sua guarda dentro de padrões adequados de conservação, julgamos importante a divulgação de algumas soluções eficazes e econômicas no que se refere às técnicas de conservação preventiva ou restauro.

Durante o período de preparação para transferência do seu acervo para um local construído e preparado especificamente para

(*) Departamento de Antropologia. Universidade Católica Dom Bosco. Museu Dom Bosco. Campo Grande, MS. Aivone Carvalho Brandão etno@terra.com.br; Dulcília Lucia de Oliveira Silva dulcilia@ucdb.br recebê-lo, o Museu das Culturas Dom Bosco da Universidade Católica Dom Bosco de Campo Grande, buscando constituir-se num espaço de interação dialógica, promoveu várias atividades por meio de consultorias com inúmeras personalidades envolvidas com questões museológicas, museográficas e expográficas, entre as quais destacamos a participação de Gedley Belchior Braga do Museu de Arqueologia e Etnologia da Universidade de São Paulo, que já esteve no Museu por três vezes, orientando curadores e técnicos sobre como adequar o acervo e o novo espaço às normas ideais de conservação preventiva.

Dentre as atividades realizadas e supervisionadas pela restauradora italiana Claudia Kusch, a 
convite da curadora do Departamento de Etnologia do Museu Dom Bosco, Aivone Carvalho, destacamos duas: a Máscara Veste de Lágrimas, pertencente à coleção Povos do Rio Uaupés, dados o grau de dificuldade apresentado e as soluções encontradas; e um Pariko, pela insólita participação, como donos originais da técnica de produção desse objeto, de dois Bororo, Agostinho Eibaidjwu e Ailton Meri Ekureu como supervisores do processo de intervenção.

\section{Primeiro caso: intervenções na máscara Veste} de Lágrimas

As máscaras Veste de Lágrimas têm a forma de um camisolão feito de tronco de tucurí, cortado no comprimento e espessura desejados. Bate-se a casca com um macete até que a parte lenhosa seja eliminada e o líber se desprenda. É costurado com fio de tucum e tem a parte inferior desfiada em longas fitas que recobrem as pernas (Fig. 1). As pinturas e o formato da cabeça dependem do animal que representam. Para povos como os Taryana são objetos sagrados e não podem ser vistos por mulheres e crianças. Já para os Wanãna e Kubêmãna são máscaras fúnebres, mas não sagradas. Esses povos habitam o Alto Rio Negro, na região do rio Uaupés, na Amazônia brasileira.

A máscara pertencente à coleção dos povos do rio Uaupés exposta na Sala das Máscaras do Museu Dom Bosco, datada de 1961 e inventariada sob número 10740 com a integridade seriamente comprometida, apresentava a parte superior presa ao corpo apenas por uma faixa da fibra vegetal bastante ressecada com presença de poeira, despigmentação, com costuras laterais não originais e com vários pontos destruídos por insetos, enfim com a integridade seriamente comprometida. (Figs. 2 e 3 )

Foi estudada atentamente pela equipe e a preocupação da curadora do departamento responsável era de que as máscaras continuassem com aparência de leveza, como se flutuassem, afinal são usadas em danças fúnebres, simbolizando as almas que ganham o espaço.

A máscara foi higienizada com aspirador de pó e vaporizador com água destilada para eliminar o ressecamento das fibras. Logo após, cuidadosamente restaurada observando técnicas modernas como a utilização de papel japonês, cola de tilose

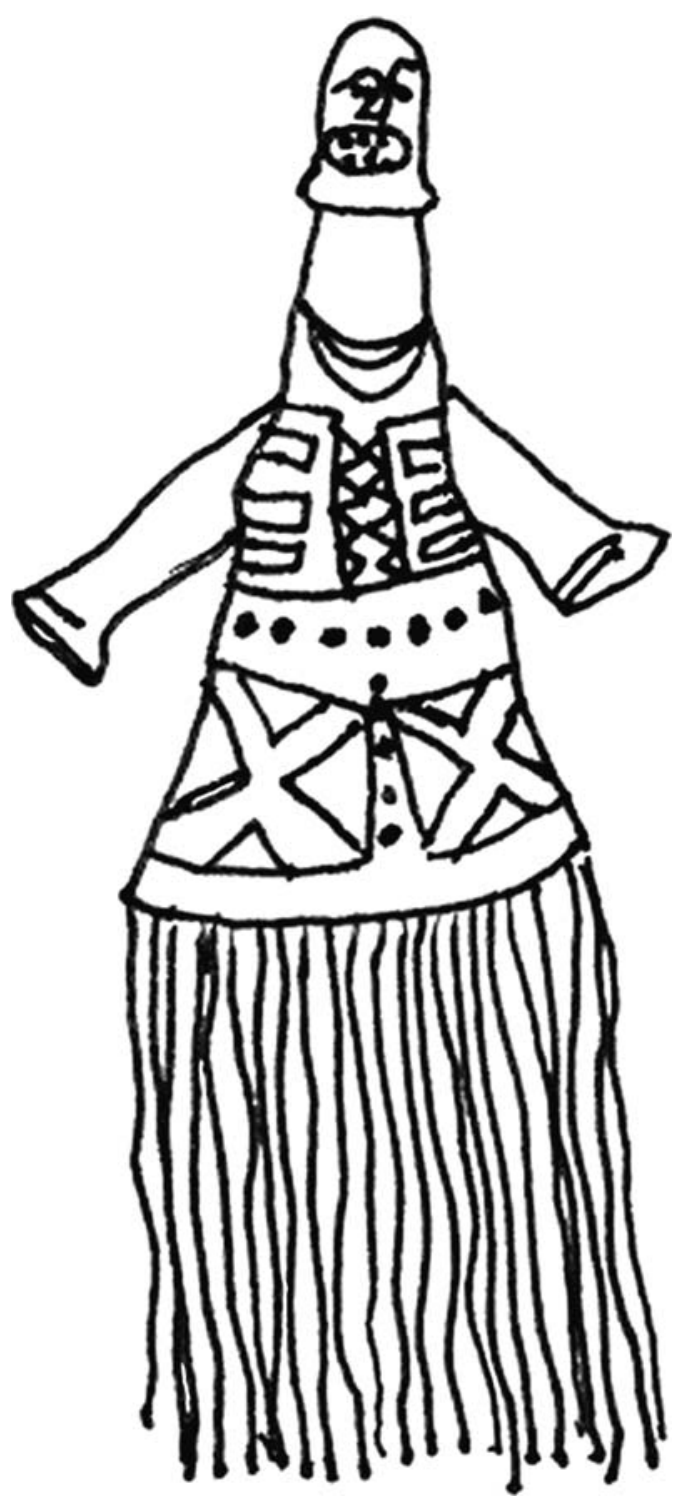

Fig. 1.

e, como estava muito danificada ao longo do pescoço, foi utilizado um pedaço de fibra vegetal (matéria prima do próprio objeto) coletada anteriormente na região proveniente da máscara, observando sempre o aspecto histórico da peça.

Com a mesma preocupação com a característica aérea do objeto passamos para a criação de um suporte conservativo que pudesse servir também para as máscaras que seriam expostas no novo espaço. Para tal, foram utilizados os seguintes materiais (Quadro). 


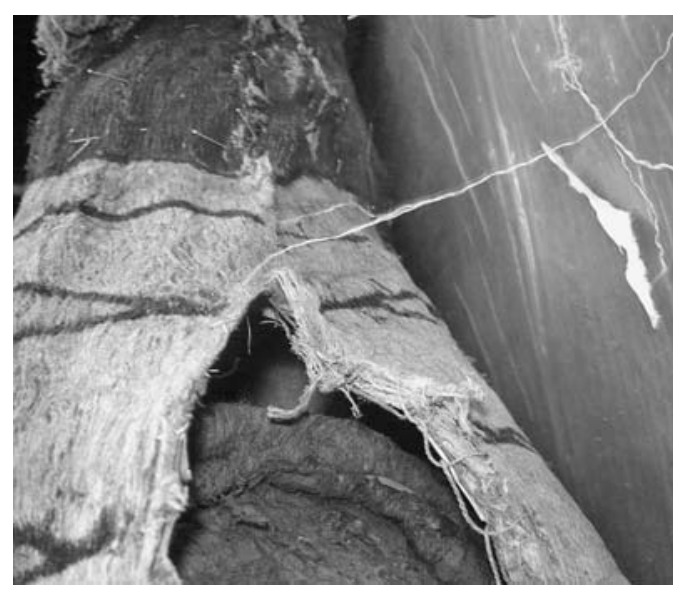

Fig. 2.

\section{Montagem do suporte}

Para a montagem do suporte, utilizou-se o seguinte procedimento:

Base

Na primeira etapa do trabalho foi utilizado suporte de metal (específico para a sustentação de baner) já existente (Fig. 4a), peças de isopor em forma de sino (Fig. 4b), fita de algodão (cadarço) (Fig. 4c).

O suporte de metal foi limpo e uma peça de isopor em forma de sino foi encaixada na sua parte superior, modelada com bisturi para a retirada de um pequeno pedaço que permitisse a passagem de uma fita viés pela superfície do sino.

O viés foi medido e cortado em quatro partes, totalizando oito pontas com o tamanho de duas vezes a altura da máscara trabalhada, considerando a curva sobre a peça de isopor, preservando assim as medidas. As fitas (cadarço) foram fixadas com cola quente na peça de isopor.

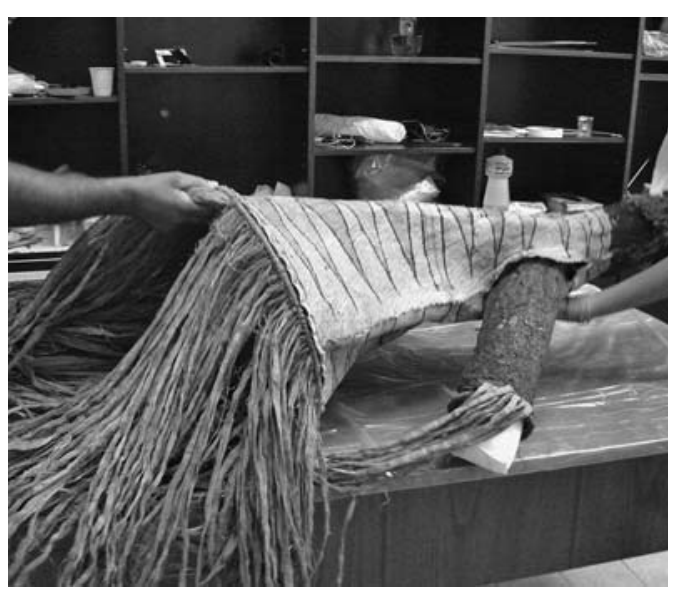

Fig. 3.

Aros

Foram utilizados como material, metal inoxidável, etafoan, cola quente, TNT e linha de algodão.

A lâmina de metal foi cortada na medida do diâmetro interno da máscara, acrescida de alguns centímetros para a emenda (Fig. 5a).

O etafoan foi modelado de acordo com o tamanho da lâmina de metal. Para testar o diâmetro do aro, o etafoan foi fixado com fita adesiva na parte externa da lâmina de metal ainda não emendada, buscando, assim, um ajuste ideal do diâmetro ao interior da máscara (Fig. 5b).

Encontrado o diâmetro ideal, realizamos a emenda temporária das duas extremidades da lâmina com fita adesiva e o etafoan foi colado na parte externa com cola quente, em seguida foi cortada e colada outra tira de etafoan na parte interna do aro (Fig. 5c).

\begin{tabular}{ll}
\hline \multicolumn{1}{c}{ Material do suporte } & \multicolumn{1}{c}{ Material de trabalho } \\
\hline \hline Suporte de metal (próprio para baner) já existente & Fita crepe \\
Peças de isopor em forma de sino & Alicate \\
Tecido não tecido (TNT) & Alfinete \\
Fita de algodão (cadarço) & Fita métrica \\
Tiras de etafoan & Bastões de silicone (cola quente) \\
Fita de metal (galvanizada) & Agulha \\
Linha de costura n.10 & Pistola de cola quente \\
Manta acrílica &
\end{tabular}




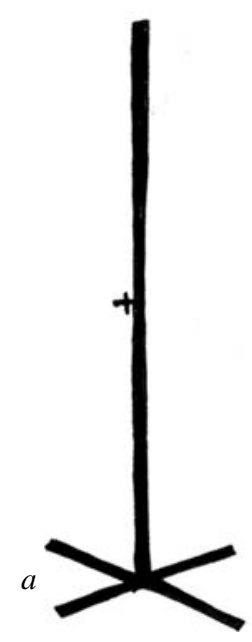

Fig. 4. a
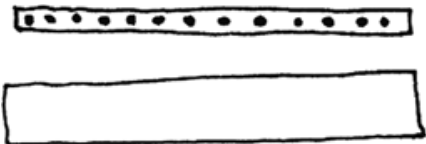

$b$
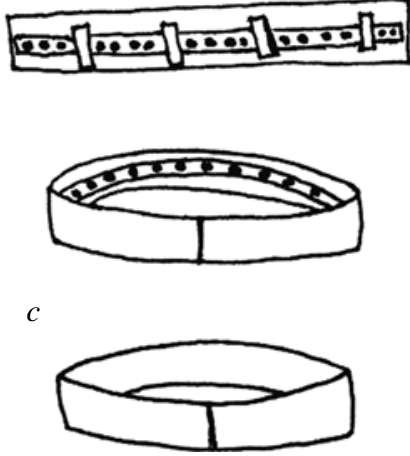

Fig. 5.
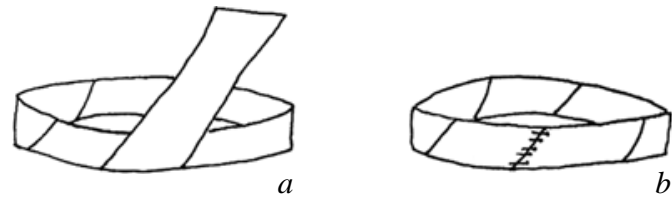

Fig. 6.
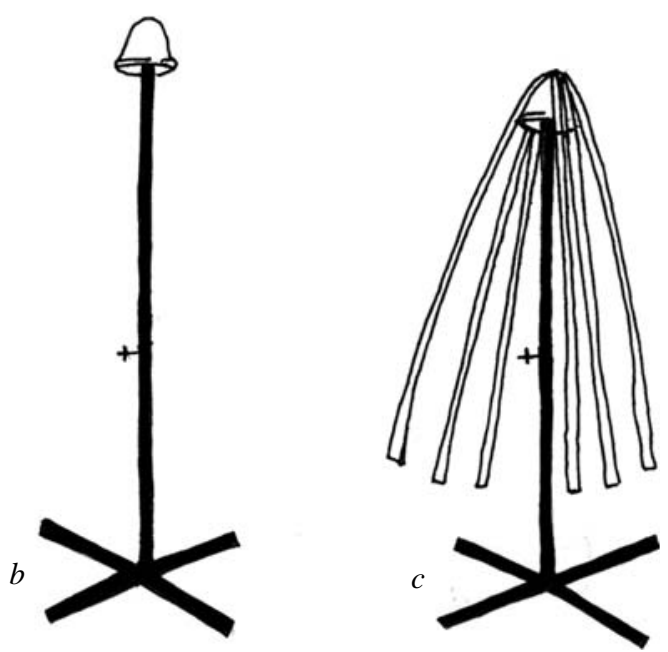

Para o acabamento dos aros, depois de confeccionados, cada um recebeu uma cobertura de TNT: foram cortadas longas tiras de $10 \mathrm{~cm}$ de largura para envolver a estrutura, em seguida arrematadas com costura (Fig. 6a e 6b).

\section{Suporte, fitas e aros}

Para a estrutura propriamente dita foram necessários três aros para dar sustentação à máscara. Mas cada máscara deverá ter uma sustentação específica.

O primeiro aro (superior) serve para dar forma à máscara e manter o volume original.

O segundo aro (central) serve de apoio para os braços dentro da máscara, apoiandose o aro dos braços no aro do suporte.

O último aro de metal sustenta o aro de cipó da saia da máscara, que fica posicionado abaixo dela.

Cada aro deve ser medido levando-se em consideração que o volume dos materiais interfere no diâmetro final.

\section{Colocação dos aros no suporte}

Para ajustar os aros e experimentá-los na máscara é indicado prender as fitas no aro por meio de alfinetes, lembrando sempre do 
cuidado com os alfinetes para que não entrem em contato com a peça e a perfurem ou rasguem.

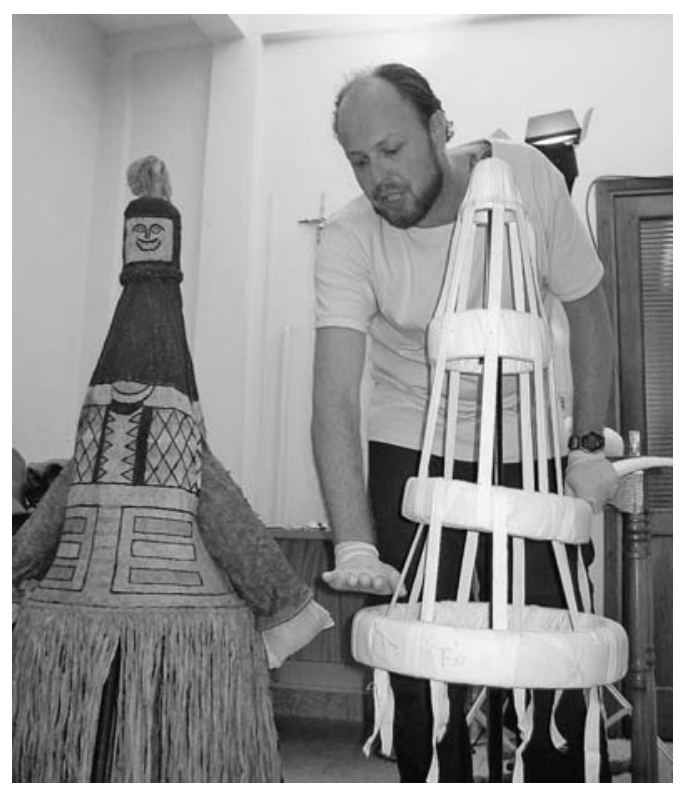

Fig. 7.

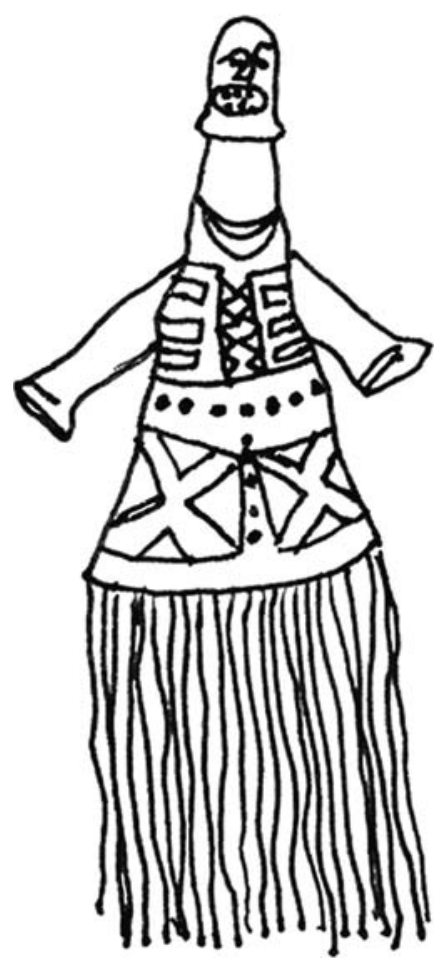

Fig. 9.
Após o ajuste, as fitas são colocadas com cola quente, costuradas no aro e o excesso de fita é cortado (Figs. 7, 8, 9 e 10).

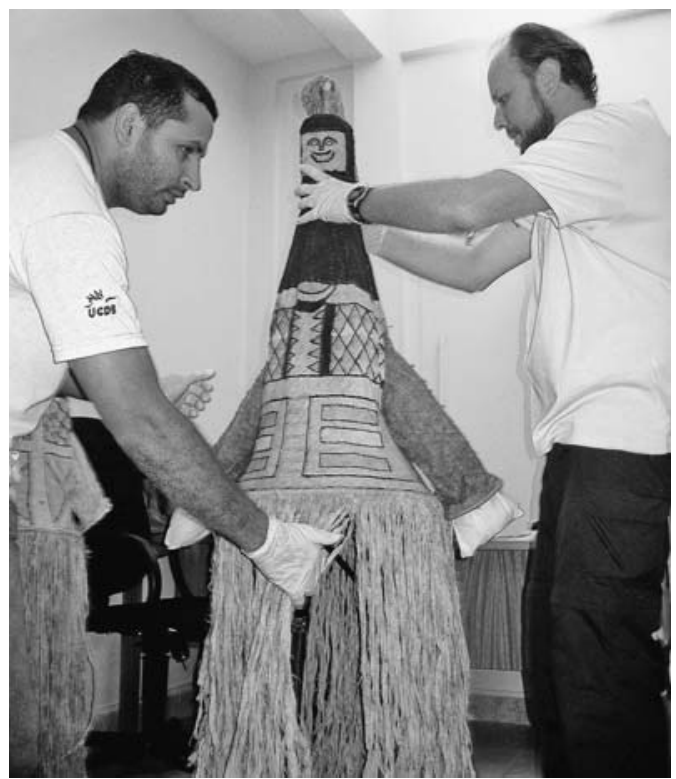

Fig. 8.

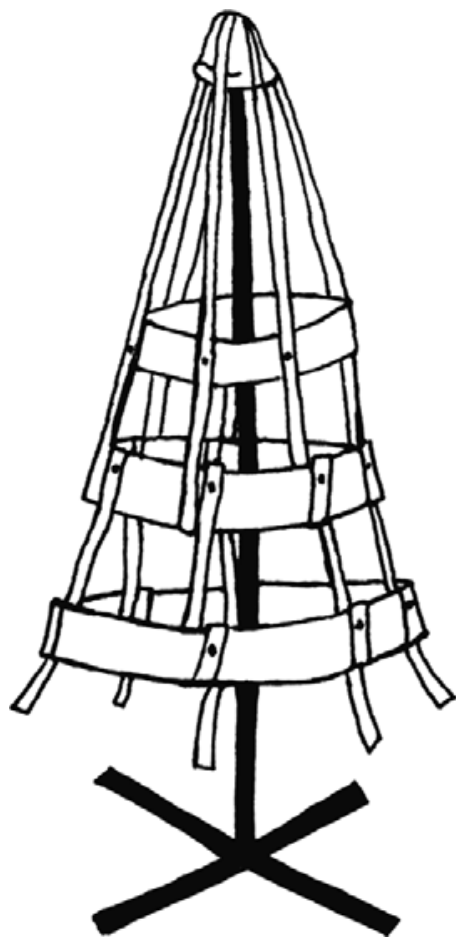

Fig. 10. 


\section{Preenchimento dos braços}

No preenchimento dos braços foram confeccionados cilindros de manta acrílica envolvidos em TNT e costurados com linha comum de costura. Para a colocação dos cilindros dentro dos braços da máscara, foi preciso retorcer os cilindros, a fim de que a manta acrílica ficasse menor que o tamanho dos braços, assim depois de colocados, os cilindros foram destorcidos para ocupar, preencher e modelar todo o espaço interior dos braços.

Após a colocação dos cilindros nos braços da máscara, o suporte vai travar a peça. Sendo assim, no caso de retirada da peça, o procedimento será o inverso começando pelos cilindros que estão no interior dos braços.

\section{Segundo caso: restauro conservativo de Pariko Bororo}

Boe et-au Kajejewu é a denominação bororo para todos os adornos usados ao redor da cabeça. O mais importante e mais significativo é o Pariko, uma rica coroa feita de penas de arara usada em todos os rituais, tanto os associados à caça ou a uma farta pesca, à nominação das crianças ou à perfuração dos ipare (rapazes) ou à perfuração dos lóbulos das orelhas das noguare (moças) quanto aos relacionados ao ciclo fúnebre.

As intervenções nos Parikos foram realizadas pelos Bororo Agostinho Eibajiwu e Ailton Meri Ekureu e acompanhados pela restauradora do Museu do Vaticano Claudia Kusch e a Curadora do Departamento de Etnologia do Museu Dom Bosco, Profa. Aivone Carvalho. Os Bororo, que haviam trazido da aldeia várias espécies de materiais específicos para a elaboração de Parikos, observaram o objeto, identificaram o problema apresentado e o material utilizado na confecção do arco quebrado, concluindo que era feito da mesma forma como ainda eram produzidos hoje (Fig. 11). De acordo com o grupo, decidiram realizar o restauro em etapas.

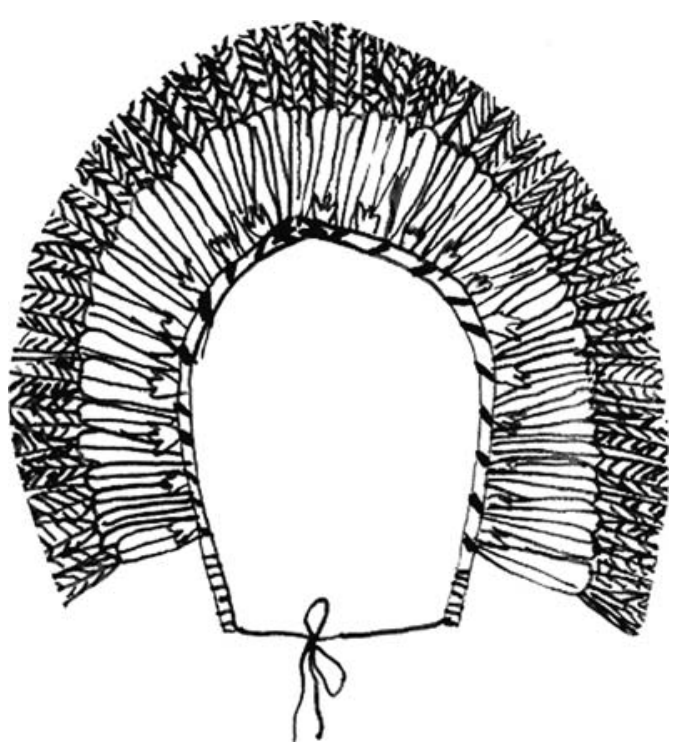

Fig. 11.

A primeira etapa deu-se na preparação dos materiais para construção de um novo arco, ressaltando que foram utilizados os mesmos materiais do arco original.

A confecção do arco ocorreu com o agrupamento das fibras de babaçu, formando um pequeno feixe preso por uma de suas extremidades (Fig. 12). As fibras foram enroladas com fios de tucum já encerados de maneira que permaneçam firmes e justas no início, e depois são espaçadas (Fig. 13). O acabamento deu-se com o ajustamento novamente da fibra, arrematada com um nó.

Depois de enrolado, totalmente, no comprimento do arco a ser restaurado, as sobras de fibras foram aparadas (Fig. 15). Posteriormente, o arco pronto foi encaixado entre os dois arcos do Pariko prendendo-se nas pontas para ajustar a curva.

A costura feita com o fio de tucum encerado foi iniciada na parte central do arco em direção a cada uma das extremidades, considerando que a nova costura reproduz a original, prendendo-a no fio da costura de ambos os $\operatorname{arcos}$ (Fig. 14).

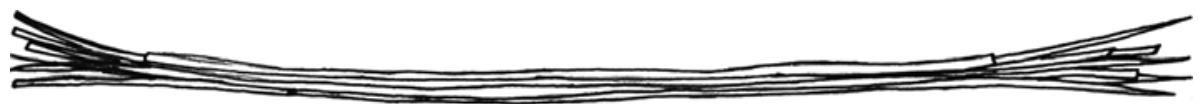

Fig. 12. 


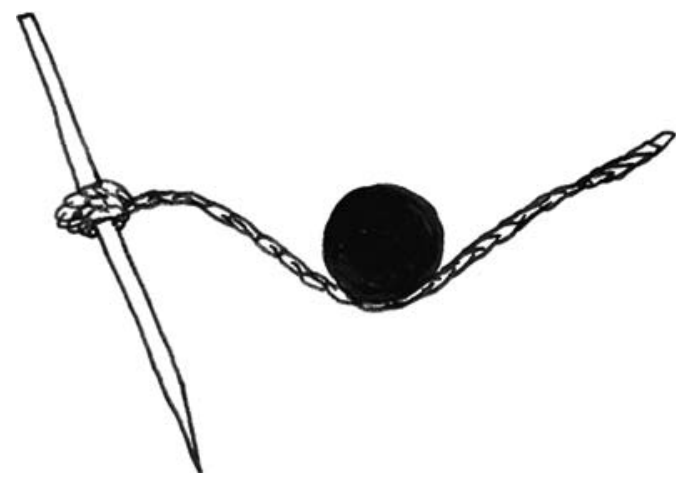

Fig. 13.

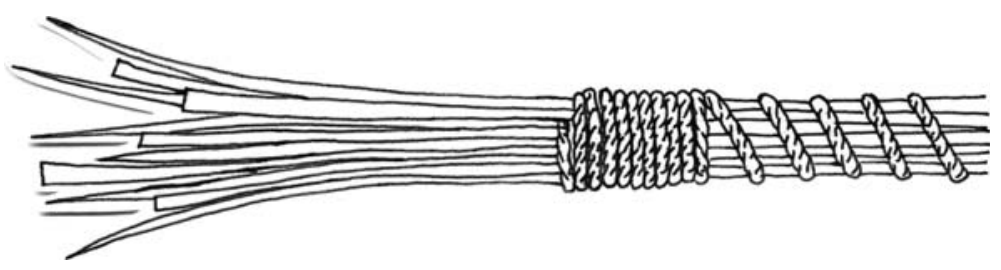

Fig. 14.

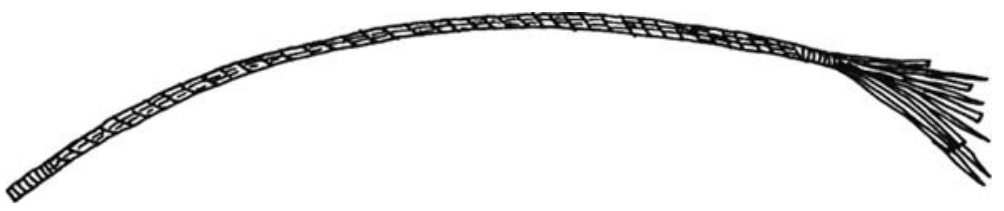

Fig. 15.

O Pariko foi restaurado conservando suas as características originais, com matéria prima trazida da própria Reserva Indígena de Meruri, porém priorizando a conservação do aspecto histórico do objeto (Figs. 16, 17 e 18).

Nesta imagem, os Bororo apresentam o resultado do trabalho à equipe, destacando todo o processo de elaboração de um Pariko e a importância de se fazer uma intervenção assistida, priorizando o emprego de material original, proveniente da própria aldeia.
Colaboraram nestas atividades, além da professora convidada Claudia Kusch, Aivone Carvalho, Dulcília Lucia de Oliveira Silva, Sérgio Sato, Dirceu Mauricio van Lonkhuijzen, Rejiane Platero Ferreira, Devane Marcos Silva Gonçalves, funcionários do Museu Dom Bosco Agostinho Eibajiwu, Ailton Meri Ekureu e Daphne Cristina Menezes Fucks Viera, reponsável pelas ilustrações, participante convidada, formada em Artes Plásticas pela Universidade Estadual de Campinas. 


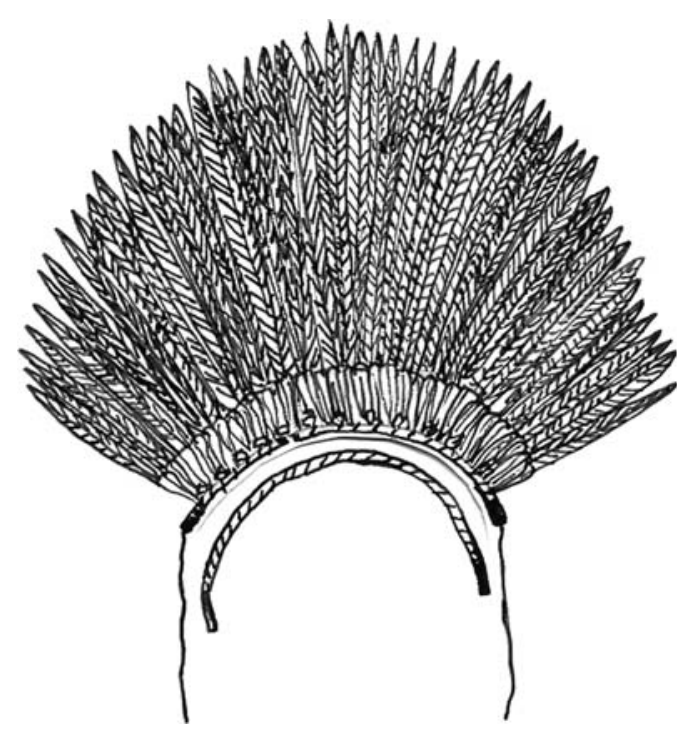

Fig. 16.

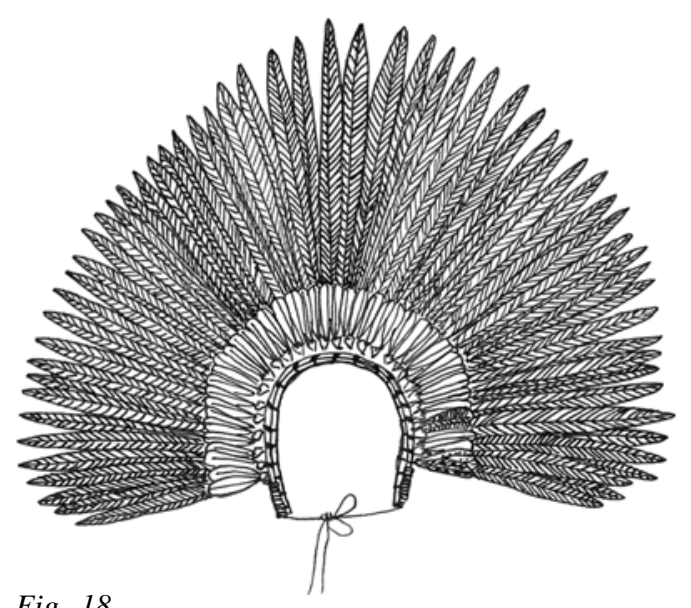

Fig. 18.

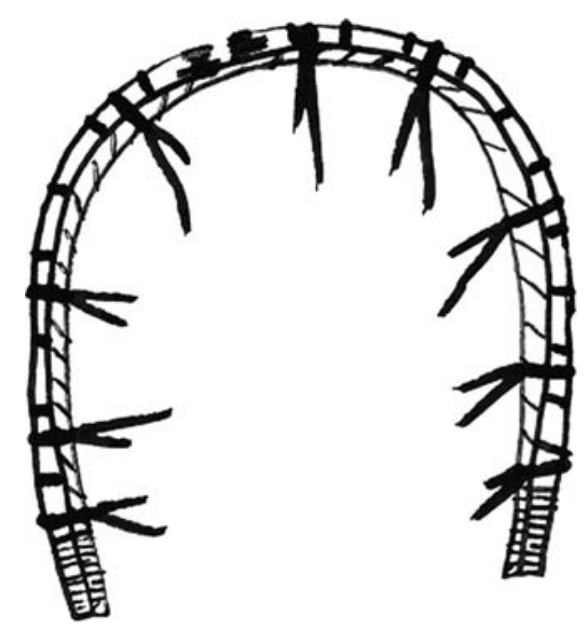

Fig. 17.

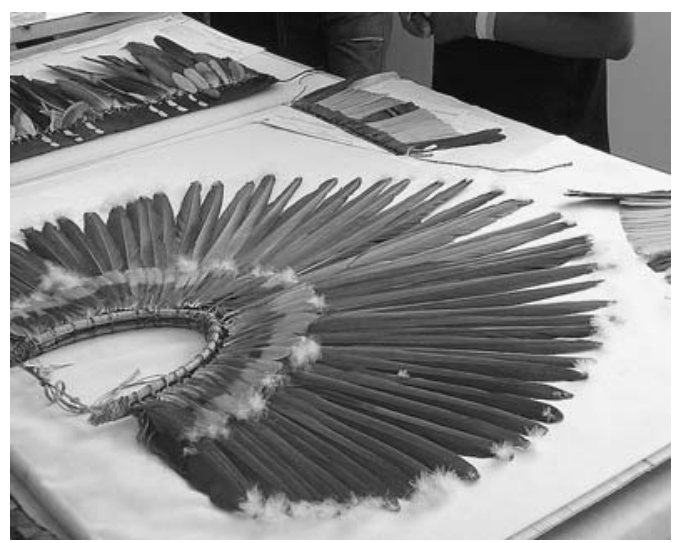

Fig. 19. 
CARVALHO, A.; OLIVEIRA SILVA, D.L. Conservação preventiva, intervenção e restauro em acervo etnológico: sugestões metodológicas. Rev. do Museu de Arqueologia e Etnologia, São Paulo, 15-16: 347-355, 2005-2006.

CARVALHO, A.; OLIVEIRA SILVA, D.L. Conservation, intervention and restoration in ethnographic objects: methodological suggestions. Rev. do Museu de Arqueologia e Etnologia, São Paulo, 15-16: 347-355, 2005-2006.

ABSTRACT: This article points that in the modern culture of conservation, the historic authenticity of cultural property arises as a prioritary value, asserting that restoration is never based on aleatory hypothesis. Being understood that for each object and site to restore we have to realize a specific and singular study from which a peculiar planning solution can spring, it is moreover possible to identify a research process for the restoration based on "diagnosis", where we effectuate the reading and the recognition of the state of decay and we identify all the available means to guarantee the physical conservation of the work; the definition of the "plan", through which the utilization of the object is realized, for the aims proposed and within the bounds allowed by the integrated conservation and it is very important, before operating any intervention, to reach the deep and complete knowledge of the object cultural property. The working realized in the Museu Dom Bosco is based on some studies of important specialists.

UNITERMS: Brazilian Ethnography -Conservation and restoration of ethnographic material-Methodological suggestions.

Recebido para publicação em 18 de setembro de 2006. 